\title{
Effect of nano spheres on crystalization kinetics of maleic anhydride grafted polypropylene
}

\author{
S.J.A. Rizvi* and U. Sharma \\ Department of Petroleum Studies, Aligarh Muslim University, Aligarh, India, 202002. \\ *Email: javedrizvi1976@gmail.com
}

Thermoplastic nanocomposites of maleic anhydride grafted polypropylene (MA-g-PP) and monodisperse silica-nanospheres of diameter 60, 100 and $250 \mathrm{~nm}$ were prepared by melt blending in a conical twin screw microcompounder. Transmission electron microscopy (TEM) was employed to confirm the particle size (Figure 1). The tensile specimens were molded and tested using digital image correlation technique. The crystallinity was determined using differential scanning calorimetery (DSC) and wide angle X-ray diffraction (WAXD). The scanning and transmission electron micrographs show the proper dispersion of silica-nanospheres in matrix. Taguchi method [1] was employed for analysis of nonisothermal crystallization parameters. The crystallization parameters were calculated from DSC plots.

The design factors include particle size, volume fraction and cooling rate. The Avrami and Tobin parameters were calculated [2, 3]. The signal-to-noise $(\mathrm{S} / \mathrm{N})$ responses were obtained from Taguchi analysis. The characteristic trends resulted from $\mathrm{S} / \mathrm{N}$ ratio are quite meaningful for the optimization of polymer processing parameters in the light of desired crystallization parameters.

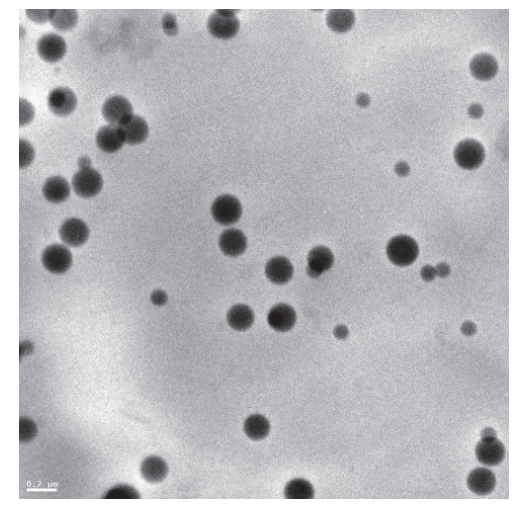

Figure 1: TEM microphotograph of PP/silicananospheres $250 \mathrm{~nm}, 3$ vol. \%

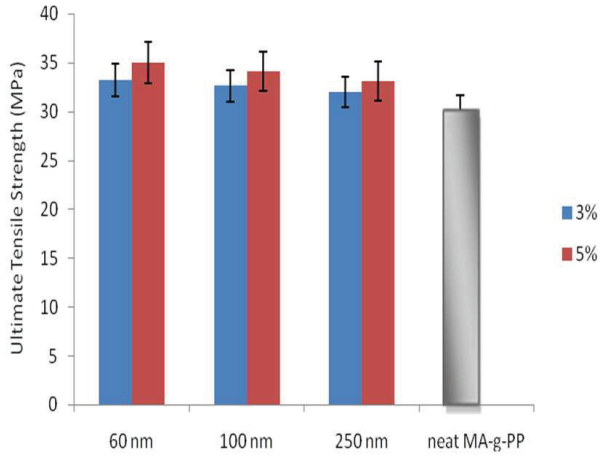

Figure 2:Ultimate tensile strength of $\mathrm{PP}$ and $\mathrm{PP} /$ silica-nanospheres nanocomposites.

The practicing polymer engineer or technologist can vary the aforesaid process variables to achieve the optimized crystallization parameters. Among the three process variables, the cooling rate and particle size were found to be most influential (as shown in Figure 2 for tensile strength) whereas some crystallization parameters (such as onset temperature, Avrami exponent and half crystallization time) were unaffected by volume fraction of nanoparticles while others have less pronounced effect of nanoparticle loading.

\section{References}

1. T. Methods, "Chapter 3 Introduction to Taguchi Methods," pp. 13-27, 1990.

2. K. Cho, F. Li, and J. Choi, "Crystallization and melting behavior of polypropylene and maleated polypropylene blends," Polymer, vol. 40, no. 7, pp. 1719-1729, Mar. 1999.

3. Y. Mubarak, P. J. Martin, and M. Ahmad, "Modeling of non-isothermal crystallization kinetics of isotactic polypropylene," vol. 42, pp. 3171-3182, 2001. 